\title{
The significant role of biomass burning aerosols in clouds and radiation in the South-eastern Atlantic Ocean
}

\section{Haochi Che ${ }^{1, \text { a }}$, Philip Stier ${ }^{1}$, Hamish Gordon ${ }^{2, b}$, Duncan Watson-Parris ${ }^{1}$, Lucia Deaconu ${ }^{1}$}

$5 \quad{ }^{1}$ Atmospheric, Oceanic and Planetary Physics, Department of Physics, University of Oxford, Oxford, OX1 3PU, UK

${ }^{2}$ School of Earth and Environment, University of Leeds, LS2 9JT, UK

anow at: Department of Geophysics, Tel-Aviv University, 69978, Israel

${ }^{b}$ now at: Engineering Research Accelerator, Carnegie Mellon University, Pittsburgh, PA 15217, United States

Correspondence to: Haochi Che (haochiche@tauex.tau.ac.il)

Mass fraction of organic carbon attributed by BBA
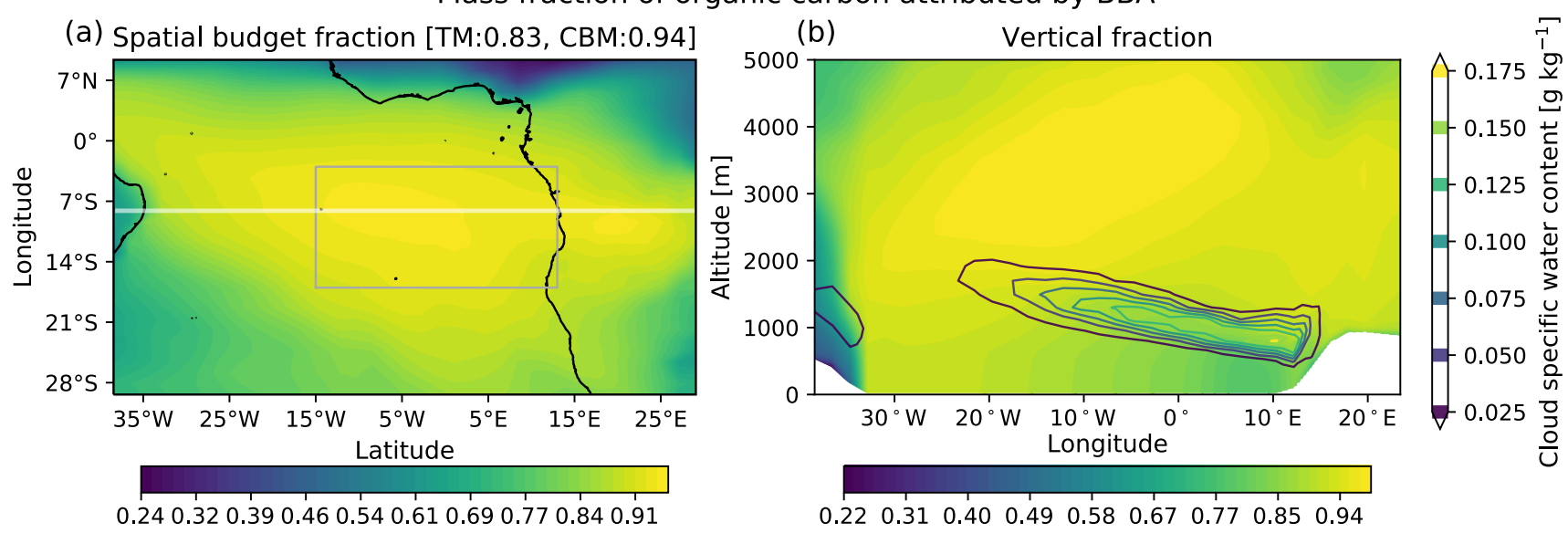

Figure S1. UKESM1 simulated mean organic carbon (OC) during July and August 2016-2017 as (a) the vertically integrated burden and (b) profile along the latitude of Ascension Island, $8.1^{\circ} \mathrm{S}$ (the white line in S1. a). The domain in S1. a, ranging

15 from $30^{\circ} \mathrm{S}$ to $10^{\circ} \mathrm{N}$ and from $40^{\circ} \mathrm{W}$ to $30^{\circ} \mathrm{E}$. The grey box in the map (cloud box) representing the cloud areas where the averaged low cloud fraction is above 0.58 . The TM is the total mean of the domain and the CBM is the mean of the cloud box. The contours in S1. b is the cloud specific water content in the baseline simulation. 

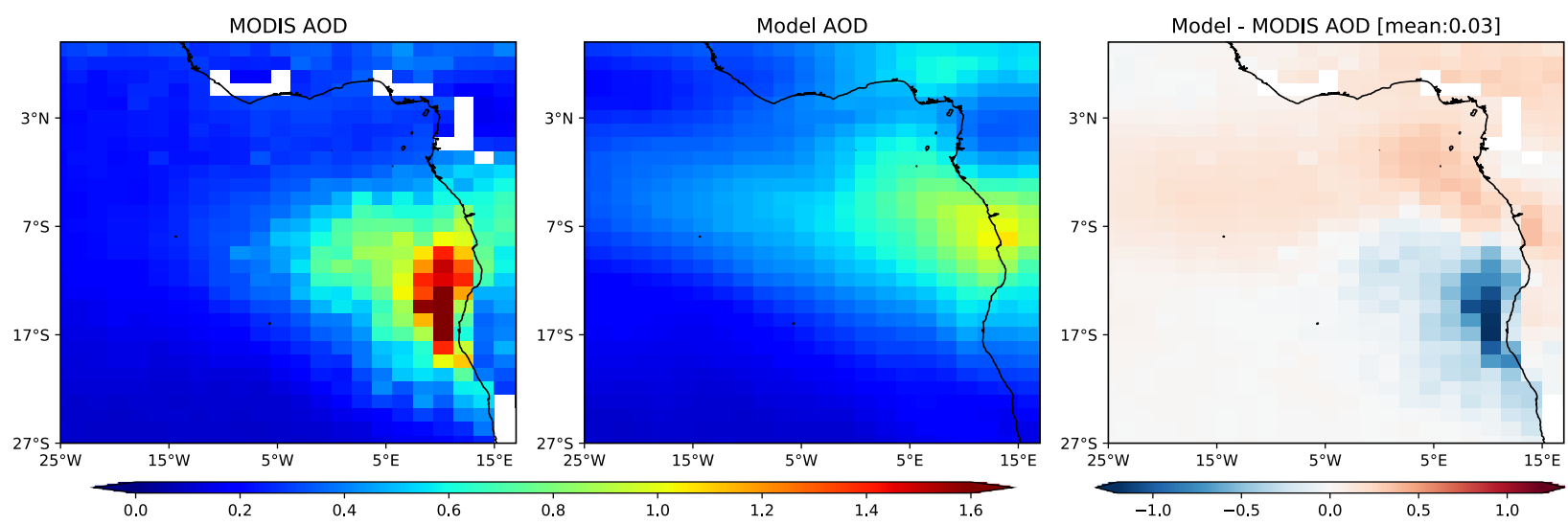

Figure S2. Mean (a) MODIS and (b) UKESM1 simulated AOD during September, 2016-2017, and the (c) differences between MODIS and the model.

5 
Cloud condensation nuclei at $0.2 \%$
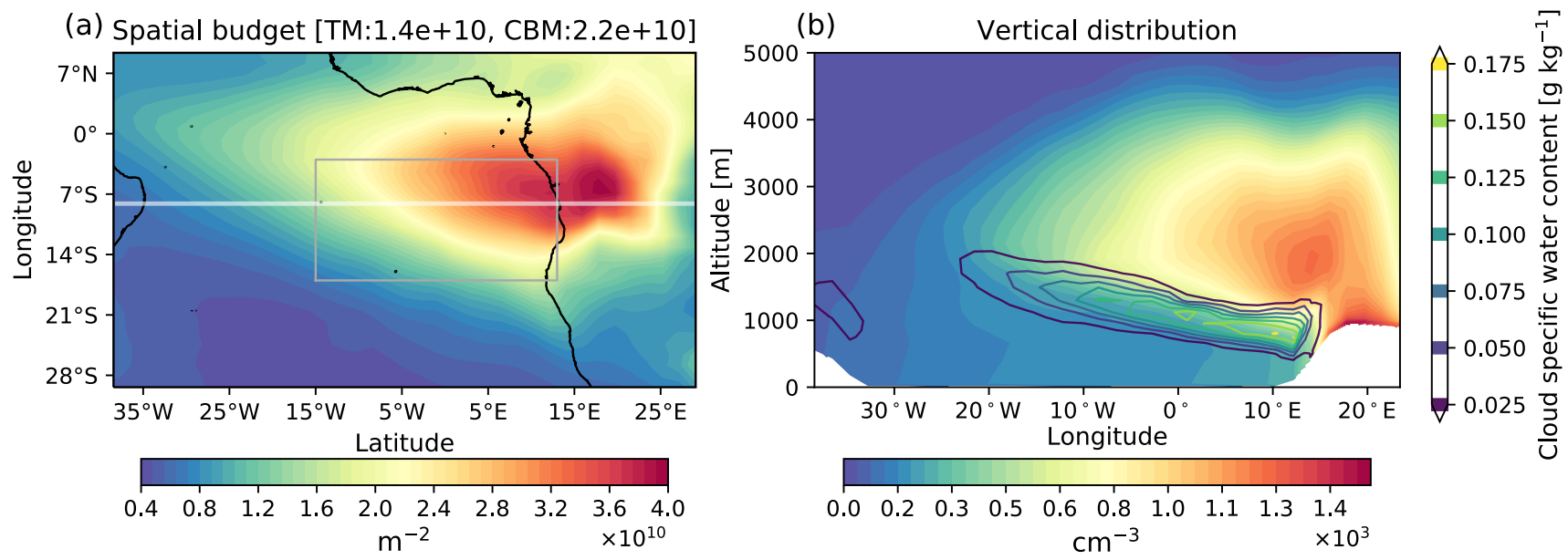

Figure S3. UKESM1 simulated mean cloud condensation nuclei at $0.2 \%$ supersaturation under standard conditions for temperature and pressure (STP) during July and August 2016-2017 as (a) the vertically integrated burden and (b) profile along the latitude of Ascension Island, $8.1^{\circ} \mathrm{S}$ (the white line in Fig. 3a). The domain in Fig. 3a, ranging from $30^{\circ} \mathrm{S}$ to $10^{\circ} \mathrm{N}$ and

5 from $40^{\circ} \mathrm{W}$ to $30^{\circ} \mathrm{E}$, is the areas this paper interested in. The grey box in the map (cloud box) representing the cloud areas where the averaged low cloud fraction is above 0.58 . The TM is the total mean of the domain and the CBM is the mean of the cloud box. The contours in Fig. $3 \mathrm{~b}$ is the cloud specific water content in the baseline simulation.

10 


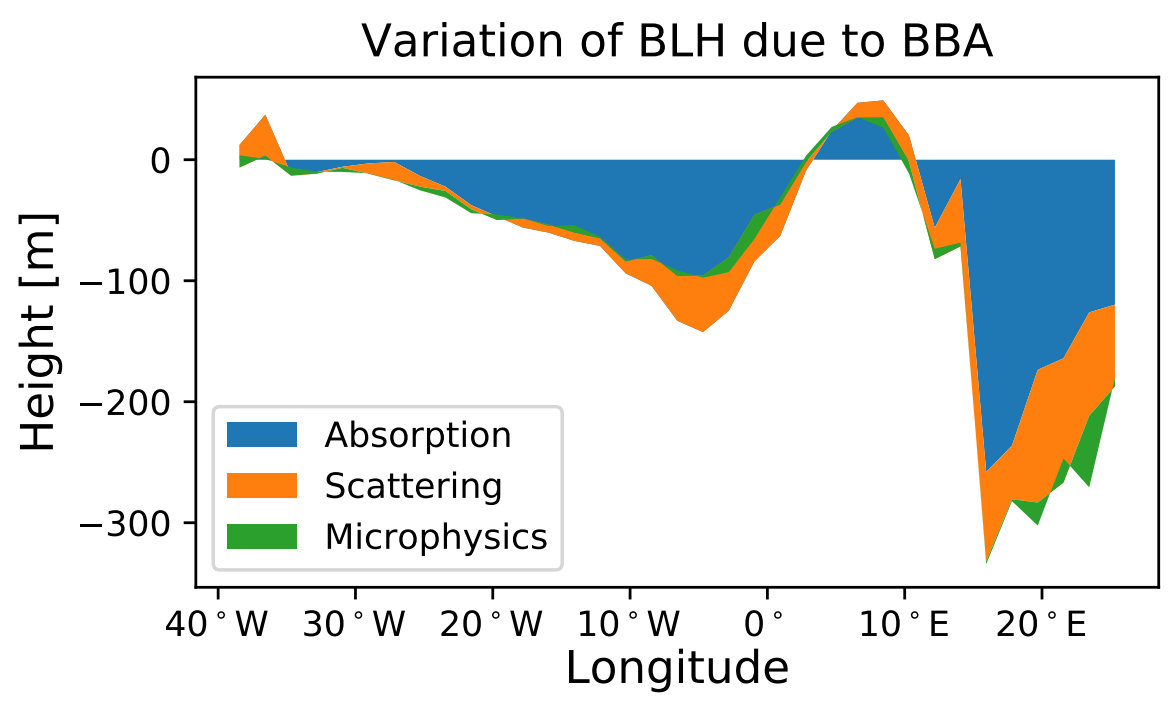

5

Figure S4. UKESM1 simulated mean variation of boundary layer height (BLH) due to BBA during July and August 20162017 along the latitude of Ascension Island, 8.1 $\mathrm{S}$. The green colour is the variation of the BLH due to BBA microphysics effect, the orange colour representing the BBA scattering effect and blue is the scattering effect.

10 


\section{Maximum supersaturation along $8.1^{\circ} \mathrm{S}$ [\%]}
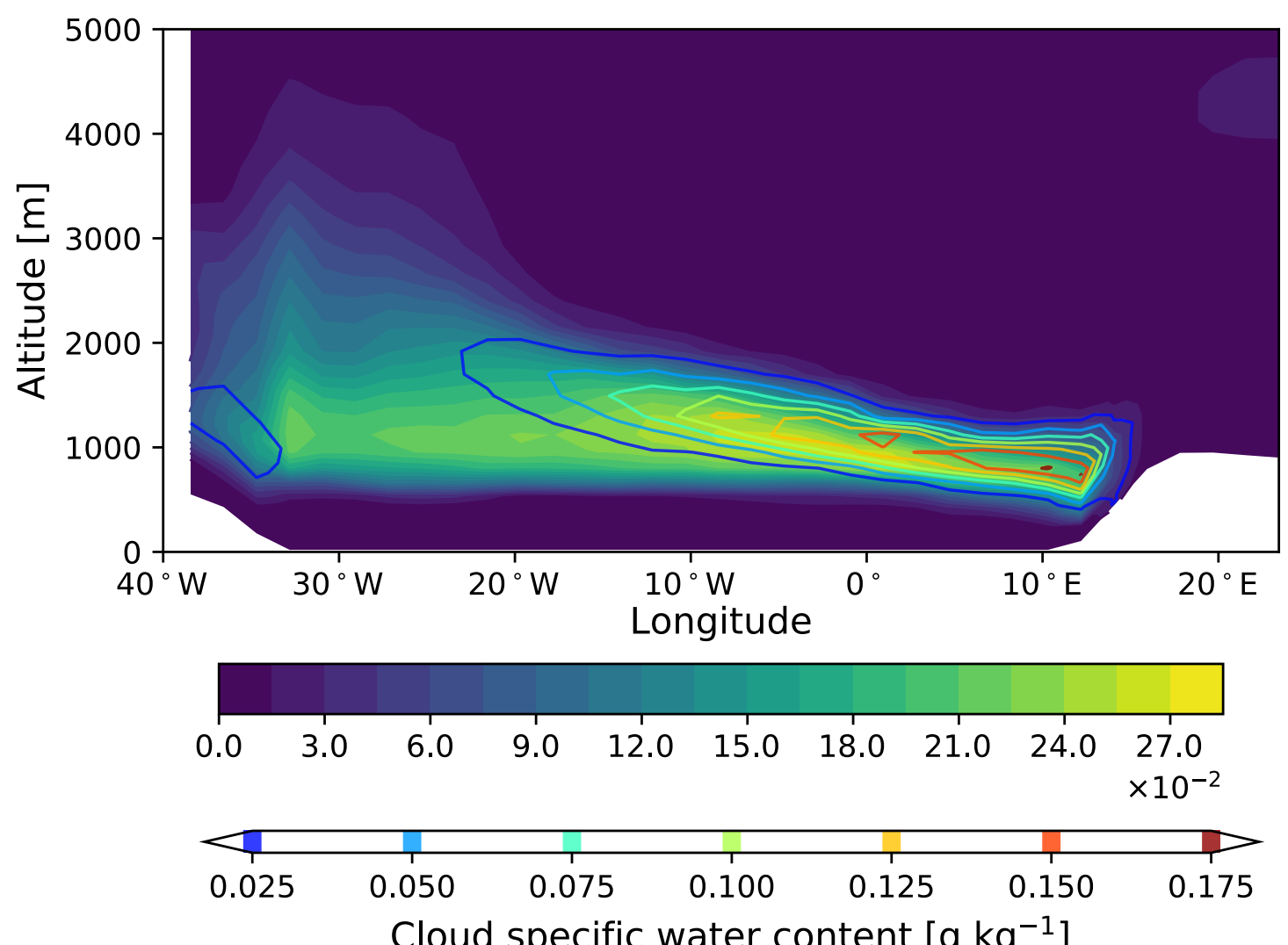

Figure S5. UKESM1 simulated mean vertical profiles of maximum supersaturation along the latitude of Ascension Island

5 during July and August, 2016-2017. The contour lines are the baseline cloud specific water content. 
Cloud droplet number concentration along $8.1^{\circ} \mathrm{S}\left[\mathrm{cm}^{-3}\right]$
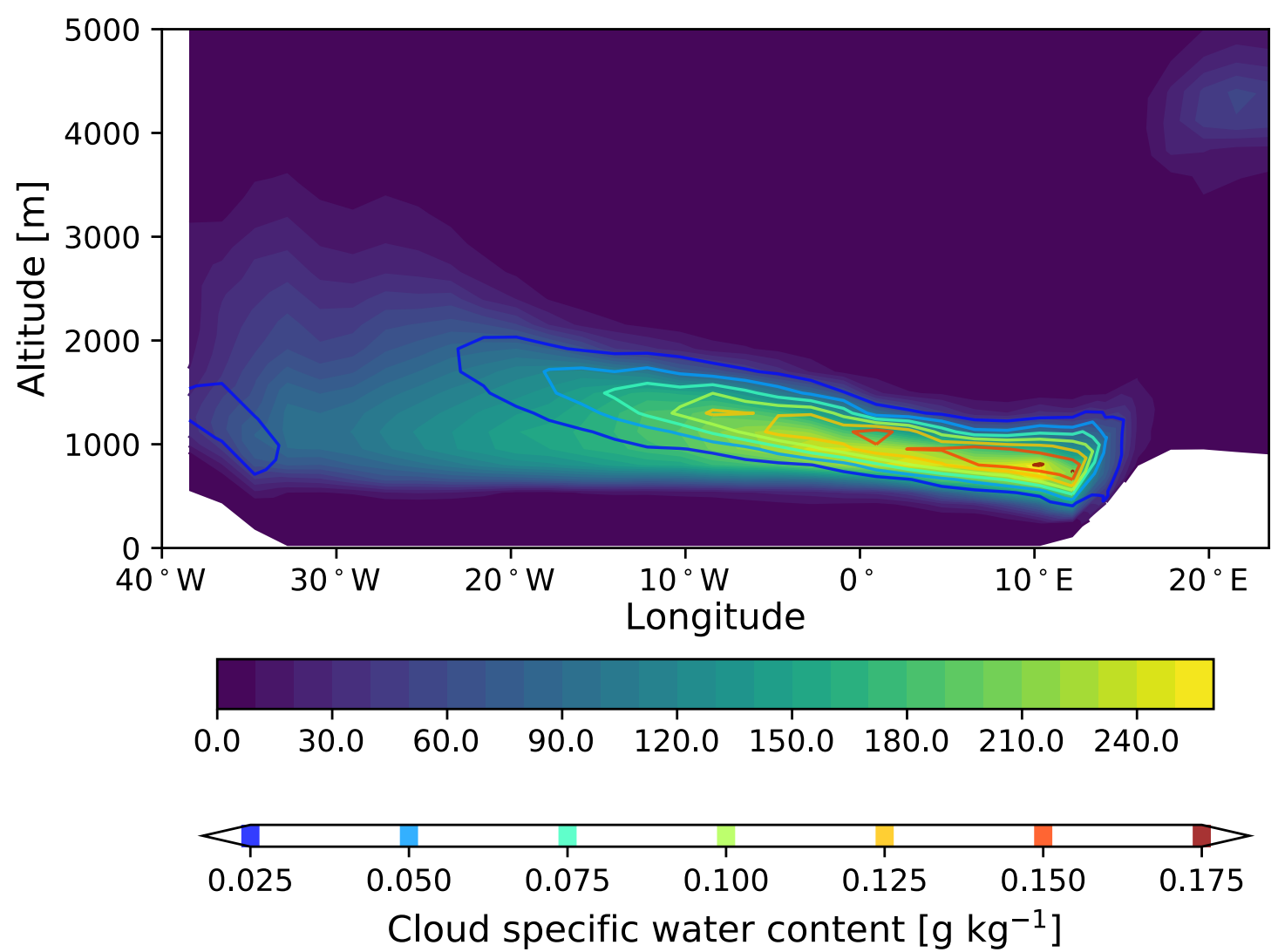

Figure S6. Same as Figure S5 but for the cloud droplet number concentration. 


\section{Liquid water path [TM:56.7, CBM:68.1] [g $\left.\mathrm{m}^{-2}\right]$}
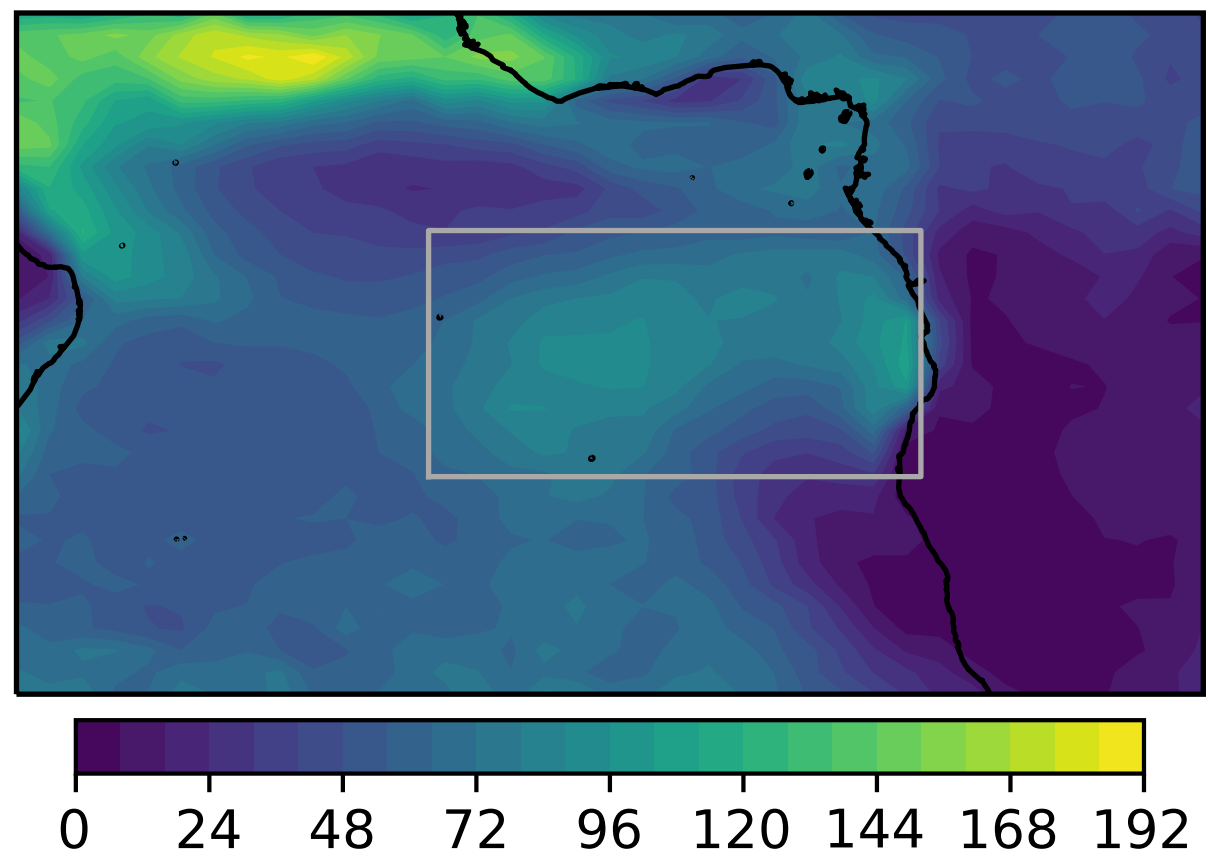

Figure S7. UKESM1 simulated mean spatial distribution of cloud liquid water path during July and August, 2016-2017. The domain range is from $30^{\circ} \mathrm{S}$ to $10^{\circ} \mathrm{N}$, and from $40^{\circ} \mathrm{W}$ to $30^{\circ} \mathrm{E}$. The $\mathrm{TM}$ is the total mean of the domain and the CBM is the mean of the cloud box (the grey box on the map) representing the areas where the average low cloud fraction is above 0.58. 


\section{Cloud albedo [TM:0.449, CBM:0.486]}
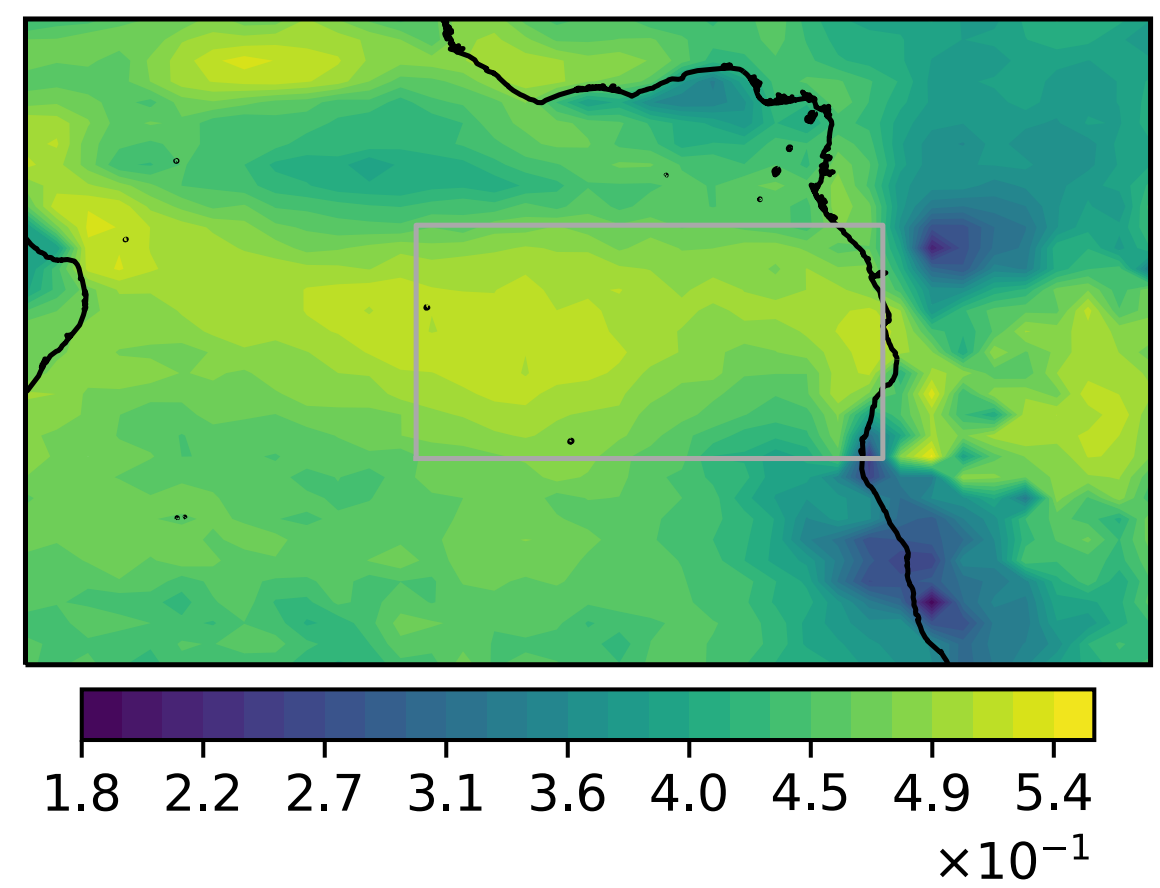

Figure S8. UKESM1 International Satellite Cloud Climatology Project (ISCCP) simulated mean spatial distribution of cloud albedo during July and August, 2016-2017. The domain range is from $30^{\circ} \mathrm{S}$ to $10^{\circ} \mathrm{N}$, and from $40^{\circ} \mathrm{W}$ to $30^{\circ} \mathrm{E}$. The TM is the total mean of the domain and the CBM is the mean of the cloud box (the grey box on the map) representing the areas where the average low cloud fraction is above 0.58 .

10 